\title{
A ESCOLA E A CONVIVÊNCIA DEMOCRÁTICA
}

\author{
SHCOOL AND DEMOCRATIC COEXISTENCE
}

Amanda Luiza Weiler Pasini ${ }^{1}$

Marcele Pereira da Rosa Zucolotto ${ }^{2}$

\section{RESUMO}

Fazendo parte de um projeto de pesquisa que visa refletir sobre a educação e a convivência democrática, o objetivo desse trabalho é refletir sobre a importância conferida pela escola para essa questão. Nessa pesquisa de cunho qualitativo foram utilizados, além da literatura, dados coletados por meio de entrevistas semiestruturadas realizadas com seis professoras de uma escola pública de ensino fundamental do interior do Rio Grande do Sul. Como resultados, pode-se perceber envolvimento e preocupação das professoras com a questão da convivência, mas que as ações executadas neste sentido acabam sendo realizadas de maneira individuais e não contam com a coletividade do ambiente escolar para a reflexão sobre isso. Este estudo mostra que encarar e discutir sobre a questão da convivência escolar é algo extremamente necessário na atualidade. E, nesta direção, aponta-se para a escola como um dos espaços mais importantes para essa discussão, um lugar privilegiado para promover, desde cedo, uma convivência respeitosa e democrática.

Palavras-chave: Convívio. Democracia. Escola.

\begin{abstract}
As part of a research project that aims to reflect on education and democratic coexistence, the objective of this work is to reflect on the importance given by the school to this issue. In this qualitative research, in addition to the literature, data collected through semi-structured interviews conducted with six teachers from a public elementary school in the interior of Rio Grande do Sul were used. As a result, we can see the teachers' involvement and concern with the issue of coexistence, but that the actions carried out in this sense end up being carried out individually and do not rely on the collectivity of the school environment for reflection on this. This study shows that facing and discussing the issue of school coexistence is something extremely necessary today. And, in this direction, the school is pointed out as one of the most important spaces for this discussion, a privileged place to promote, from an early age, a respectful and democratic coexistence.
\end{abstract}

Keywords: Conviviality. Democracy. School.

\footnotetext{
Acadêmica do Curso de Psicologia da Universidade Franciscana - UFN. E-mail: amandalpasini@hotmail.com, ORCID: https://orcid.org/0000-0002-3806-7441

Orientadora do trabalho. Doutora em Psicologia Social e Institucional. Professora do Curso de Psicologia e do Mestrado em Ensino de Humanidades e Linguagens da Universidade Franciscana - UFN. E-mail: marcele.rosa@ufn.edu.br, ORCID: https://orcid.org/0000-00026856-8626.
} 


\section{Introdução}

O presente trabalho faz parte de uma pesquisa sobre a educação escolar e a convivência democrática, que buscou refletir sobre como os/as professores/as de uma escola pública de ensino fundamental do interior do Rio Grande do Sul percebem as questões relacionadas à convivência democrática e qual a importância conferem a essa temática.

A escola é uma instituição extremamente complexa que muitas vezes parece estar alheia aos acontecimentos e avanços ocorridos no último século, pois utiliza-se das mesmas concepções de educação desde seu princípio. Para Mosé (2013), sua forma atual é obsoleta e já perdeu o prazo de validade.

Apesar disso, a escola, por ser um dos primeiros lugares de socialização e comportar uma grande diversidade humana e cultural, torna-se, também, a maior oportunidade de convívio democrático existente. No entanto, para a mesma autora (MOSÉ, 2013), alguns dos problemas mais graves da humanidade - as relações e a convivência entre as pessoas - provêm da educação, que falha em ser lugar de preparação para vida e espaço de socialização (ZUCOLOTTO; LIMACHI; NASS, 2019c).

O espaço escolar acaba se tornando um lugar onde se promovem não apenas conhecimentos, mas também valores importantes para a vida. Assim, as/os professoras/es, muitas vezes, acabam substituindo algumas famílias na orientação para a vida social, sexual, profissional, além de serem convocados a ensinar valores e ideais indispensáveis, especialmente, à convivência, como respeito, ética e solidariedade (BOCK, 2008).

Deste modo, o objetivo desse estudo configurou-se em refletir sobre qual a importância conferida pela escola para a questão da convivência democrática. Nessa pesquisa de cunho qualitativo foram utilizados, além da literatura, dados das entrevistas semiestruturadas realizadas com seis professoras de uma escola pública de ensino fundamental do interior do Rio Grande do Sul.

Como resultados, pode-se perceber envolvimento e preocupação das professoras com a questão da convivência, mas que as ações executadas neste sentido acabam sendo realizadas de maneira individuais e não contam com a coletividade do ambiente escolar para a reflexão sobre isso.

Mesmo havendo certa discordância entre as ações realizadas, torna-se fundamental lembrar que, apesar das inúmeras tentativas de melhoria por parte de certos educadores, o problema da convivência escolar é mais complexo e maior que o abrangido pela sala de aula. No 
entanto, a escola acaba sendo um dos ambientes mais propícios e relevantes para que estas questões possam ser colocadas e debatidas na atualidade.

Este estudo mostra que encarar e discutir sobre a questão da convivência escolar é algo extremamente necessário na atualidade. E, nesta direção, aponta-se para a escola como um dos espaços mais importantes para essa discussão, um lugar privilegiado para promover, desde cedo, uma convivência respeitosa e democrática.

\section{A escola na atualidade e a questão da convivência democrática: questões teóricas}

A escola é uma instituição da sociedade que trabalha a serviço da mesma e por ela é sustentada, utilizando-se de funções especializadas a fim de responder a necessidades sociais. Sua principal função é a de preparar as crianças para viverem no mundo adulto; ensiná-las conteúdos indispensáveis para a vida pessoal, social e profissional futura, bem como conhecimentos básicos sobre as regras e valores sociais (BOCK, 2008).

Sua estrutura oscila entre a ideia de emancipação pela razão e disciplinamento pelo controle; lugares de pensamento e criação, mas também de vigilância e exclusão. A herança pesada das antigas organizações de estruturas piramidais, de hierarquia rígida, que fizeram do conhecimento algo a ser assimilado, memorizado e não pensado de modo crítico ainda influencia a educação atual.

$\mathrm{O}$ antigo modo de ensino, baseado somente no respeito à autoridade do professor não se mostra mais tão eficiente, pois as crianças da atualidade não sabem por que exatamente haveriam de segui-lo, surgindo para muitos estudantes como uma postura descontextualizada em sala de aula. Além disso, segundo Foucault (1987), para dar conta do grande número de alunos em sala de aula e da dificuldade na construção de métodos que permitissem regulamentar simultaneamente a atividade de toda uma turma, houve muita desordem, confusão e foi necessária a organização dos controles, para isso, utilizou-se a metodologia de fiscalização empregada nas oficinas e fábricas.

A configuração utilizada na escola é a mesma há décadas, "é a do período colonial, se passa um verniz de modernidade, mas ele continua o mesmo" (MOSÉ, 2013, p. 269), sendo baseada tanto nas escolas militares, quanto nas fábricas, justamente para garantir melhor controle e observação por parte do supervisor. Para isso, há as combinações: as fileiras, os lugares específicos na sala, entre outras, tornando possível realizar, ao mesmo tempo, uma vigilância geral e individual; constatar a presença, a aplicação, compará-los entre si, classificálos segundo sua habilidade e rapidez. Estes elementos fizeram "funcionar o espaço escolar como 
uma máquina de ensinar, mas também de vigiar, de hierarquizar, de recompensar" (FOUCAULT, 1987, p. 173).

No Brasil, esse modelo de educação foi reforçado e instituído durante o período da ditadura militar. As escolas brasileiras, já baseadas na organização fabril, tornaram-se reféns desse sistema disciplinar instaurado em todas as áreas da sociedade, que negava e combatia toda forma de pensamento, esvaziando o caráter reflexivo e crítico das disciplinas que não foram retiradas dos currículos. Restou somente as características desejadas para aquele momento histórico: disciplina, submissão e obediência e, com isso, afastou-se mais ainda a escola das questões diárias das pessoas e dos desafios da sociedade. O legado dessa época de autoritarismo ainda não foi superado, mesmo com transformações desde o ocorrido, o empobrecimento e a instrumentalização do pensamento na educação escolar continuam presentes na educação, reduzindo o conhecimento à informação, e a informação ao útil (MOSÉ, 2013).

Mesmo a cultura líquido-moderna não sendo mais, necessariamente, uma "cultura da aprendizagem e da acumulação" (BAUMAN; MAZZEO, 2013, p. 23), como as registradas nas etnografias, ela é assim retratada pelas instituições de ensino. Para Mosé (2013), são ensinadas informações desconexas e o saber é apresentado de maneira tão fragmentada que os conhecimentos, posteriormente, acabam não se unindo numa reflexão sobre as questões que permeiam a vida cotidiana. Os conteúdos e as matérias são tão repartidos que levam os alunos a acreditar que não estudam questões ocorridas cotidianamente, que estudam somente para fazer provas e entrar no mercado de trabalho e não para suas vidas (MOSÉ, 2013).

Esse ensino em fragmentos e conteudista promove inúmeros saberes de muitas matérias, porém fixos em seus respectivos campos de atuação, concomitantemente, vem a dificuldade em integrá-los, principalmente com a vida social, profissional e afetiva (ZUCOLOTTO; LIMACHI; NASS, 2019c). Essa característica alia-se muito bem com a necessidade da sociedade da informação: quantidades crescentes de signos descontextualizados, distribuídos constante e rapidamente, conectados entre si de forma quase que aleatória, ao invés de organizados segundo uma ordem que facilitaria o conhecimento. A partir disso torna-se cada vez mais difícil criar narrativas ou sequências significativas de desenvolvimento (BAUMAN; MAZZEO, 2013).

Ao ensinar os conteúdos de forma avulsa, a escola acaba dificultando o entendimento e, consequentemente, o surgimento de questionamentos sobre o que é estudado e, principalmente, sobre o cotidiano. Além disso, ao distanciar o saber da vida em sociedade, os estudantes dela provindos, por não saberem aplicar o aprendido de forma que os auxilie a melhor entender a sua realidade e nela atuar de forma mais eficiente, acabam ficando passivos perante a sociedade 
(BOCK, 2008) e não preparados para o debate saudável de ideias e para a convivência de modo democrático.

Implicações no ensino interferem também na convivência dos alunos entre si ou com professores. Sabe-se que "a necessidade de desenvolver, aprender e praticar a arte de conviver com os estranhos e sua diferença em base permanente e cotidiana é inescapável” (BAUMAN; MAZZEO, 2013, p. 5), porém, essa tarefa não é simples.

Para Silva, Busnello e Pezenatto (2015) a democracia consiste na possibilidade de expressão polissêmica. E, nesta direção, para o desenvolvimento de relações mais democráticas, é necessário reconhecer o outro como alguém diferente, mas que merece respeito e que esse convívio seja baseado valores e regras que instiguem essa aceitação. Para Candau (2003, p. 9), “a afirmação da democracia é incompatível com um tecido sociocultural impregnado de preconceitos, discriminações e intolerâncias, componentes configuradores de relações sociais assimétricas e desiguais".

Assim, a democracia nas relações implica reconhecer-se como parte delas e poder usufruir dessa participação. E "esse modo de vida democrático seria basilar para pensarmos em escolas democráticas, com práticas de democracia situadas na convivialidade humana, entre docentes e discentes, na comunidade escolar" (SILVA; BUSNELLO; PEZENATTO, 2015, p. 403).

O campo educacional é espaço privilegiado para essa prática da convivência democrática, pois nele a dimensão coletiva é usada para a compreensão das convenções sociais, sendo crucial para o entendimento e a aceitação dos papéis e dos limites, possibilitando o "aprender a conviver" ou a "viver juntos" (ZUCOLOTTO; LIMACHI; NASS, 2019c).

Assim, percebe-se a importância da escola como espaço de discussão e reflexão sobre as questões da convivência, tendo por objetivo uma sociedade mais democrática e que permita a participação de todos. Percebe-se também que este importante eixo da educação - o ensino da convivência democrática - ficou, historicamente, enfraquecido e que ainda há muito ainda a ser debatido no contexto escolar.

\section{Metodologia}

Esse trabalho é decorrente de uma pesquisa que visou refletir sobre a educação e a convivência democrática no contexto escolar. Por isso, baseia-se no estudo empírico de entrevistas semiestruturadas, individuais, realizadas com seis professoras de uma Escola Municipal de Ensino Fundamental de uma cidade do interior do estado do Rio Grande do Sul. A escola foi escolhida por conveniência e acessibilidade das pesquisadoras e o número de seis 
professoras participantes refere-se àquelas que se interessaram em participar da pesquisa e que tiveram disponibilidade para tal.

Trata-se de um estudo de cunho qualitativo, pois direciona-se aos significados das relações humanas a partir de diferentes pontos de vista, além de utilizar-se da interação entre o pesquisador e o sujeito para produzir o conhecimento (STAKE, 2011). Ademais, fez-se também uma revisão bibliográfica embasada em livros, artigos e produções anteriores ao projeto, com objetivo de construir um aparato teórico sobre a temática em questão que pudesse contribuir para a análise dos dados.

Por envolver seres humanos, a presente pesquisa foi realizada conforme os preceitos a Resolução 510/2016 do Conselho Nacional de Saúde (BRASIL, 2016), assegurando os direitos das participantes, o sigilo, a liberdade de participação, recuo ou desistência. Para isso, o projeto foi encaminhado para avaliação do Comitê de Ética em Pesquisa da Universidade onde a pesquisa fora desenvolvida, via Plataforma Brasil. Após ser aprovado, sob o n. CAAE 03862618.9.0000.5306, as entrevistadas assinaram, cada uma, o Termo de Consentimento Livre e Esclarecido, onde constam explicações, objetivos e todos os passos da pesquisa, além de sanar todas as dúvidas que elas pudessem apresentar. Salienta-se, ainda, que, para respeitar o sigilo, as entrevistadas serão mencionadas aqui como A, B, C, D, E e F.

Além disso, cabe destacar que os dados encontrados foram analisados segundo a teoria da análise de conteúdo de Bardin (2010) e foram divididos em categorias para melhor estudo e compreensão. Baseando-se nas respostas decorridas, o presente trabalho pretende discorrer sobre a categoria que aborda a importância conferida pelas professoras às questões relacionadas à convivência democrática.

\section{Resultados e Discussão}

A disciplina é presente em basicamente todos os âmbitos da sociedade. Na educação, uma relação de fiscalização definida e regulada, foi se consolidando como um mecanismo inerente que multiplica sua eficiência; além de ser percebido como aquele que facilita o andamento da aula e a organização escolar, pois "garante a obediência dos indivíduos, mas também uma melhor economia do tempo e dos gestos" (FOUCAULT, 1987, p. 174). Neste sentido, as professoras entrevistadas demonstraram que, embora considerassem que alguns professores pudessem agir de modo mais permissivo, a exigência de uma disciplina rígida e obediência em sala de aula ainda eram fatores fundamentais na atualidade das práticas escolares:

"Acho que hoje em dia os professores mudaram bastante né [...] mas tem uns que ainda são bem tradicionais, 
assim nesse sentido, o aluno tem que obedecer, não tem conversa." (Entrevistada F)

"[...] acho que vai muito de perfil de professor. Tem alguns professores que tem já o perfil mais dominador, autoritário e que não é errado.... Não acho que seja errado de maneira nenhuma, acho que importantíssimo. Mas acho que vai de perfil. Alguns professores têm mais facilidade, outros não. Outros vão mais pela firmeza mesmo." (Entrevistada E)

Entende-se que os excessos de disciplina, vinculados a mecanismos de controle, vigilância e submissão acabam mobilizando uma formação distanciada do questionamento crítico e, consequentemente, das possibilidades de convívio e participação democrática em sociedade. Assim, apesar de as professoras acima levarem em consideração a questão da disciplina rígida no âmbito da sala de aula, percebeu-se também que outras têm se preocupado com as questões na atualidade, como a questão da convivência escolar. As professoras abaixo demonstraram que a convivência é uma questão bastante importante de ser abordada e discutida na escola:

“[...] mas o que eu vejo aqui, de uns anos pra cá, é que a gente faz questão de ter uma boa convivência com eles e trabalhar pra que isso aconteça, porque fica bem mais prazeroso né, pros dois lados né." (Entrevistada F).

"Eu acho que a convivência, eu acho que nos facilita a convivência em sala de aula, desde a gente deixar uma tarefa pra eles, desde eles conviverem com o colega, porque eles se retrucam muito, eu acho assim que seria importante trabalhar convivência [...]" (Entrevistada E).

Assim, alguns professores, especialmente das séries iniciais estão, atualmente, tentando adotar outras formas de ensinar e transpor as principais dificuldades, a comunicação e a convivência (ZUCOLOTTO; LIMACHI; NASS, 2019b). Como os jovens e crianças estão passando cada vez mais tempo nas escolas, desde o berçário até o ensino médio, os professores e colegas acabam sendo cada vez mais partes essenciais no processo de educar. A escola acaba ocupando grande parte da vida de seus alunos; ensina conteúdos, técnicas e também valores e ideais. Neste sentido, a escola vem cada vez mais participando com as famílias na orientação para a vida sexual, profissional, para a vida como um todo (BOCK, 2008) e se tornando um espaço onde a convivência deve ser cada vez mais encarada como fundamental para a construção de uma sociedade democraticamente fortalecida.

O fato de a aprendizagem ser um processo essencialmente social, aliado ao espaço privilegiado de interação provido pela escola tende a ser muito bem aproveitado pelos professores que ensinam sobre a convivência, já que ela ocorre diariamente. Esse trabalho feito é para facilitar o convívio na sala de aula, mas também para outras questões do cotidiano fora da escola. Com isso, a educação na atualidade não seria mais somente composta pelo ensino da leitura, da escrita e da matemática, mas abrangeria também hábitos e valores da criança ou adolescente. Compreendendo que a escola é um espaço político e que reflete os confrontos da 
sociedade, é tarefa dos educadores permitir que o aluno possa aprender a participar ativamente da sociedade, pois, segundo Aranha (2006, p. 30), o estudante "compreende mal o mundo em que vive e é manipulado por aqueles que estão no poder”. Nesta direção, fica ressaltada a importância de levantar a discussão sobre a convivência democrática no campo educacional e escolar.

As professoras também mencionaram sobre a questão do apoio recebido, tanto por colegas, quanto pela escola como um todo sobre a discussão referente à convivência escolar. Algumas professoras dizem contar com este apoio, como as entrevistadas C e D:

"Eu sinto isso nos colegas, tá? E essa dedicação e essa coisa de que tem que dar certo, esse olhar em relação a essa, esse todo existe e isso que nos dá um up pra continuar sabe? Porque se fosse cada um pensando em si, ah eu não quero saber, né." (Entrevistada C).

"Sim, eu vejo que os professores têm essa preocupação com a convivência, porque senão não dá pra ensinar" (Entrevistada D).

Assim, as professoras entrevistadas acima mostram que existe uma preocupação coletiva com a questão da convivência escolar na escola em que trabalham. No entanto, a entrevistada B, traz o contrário, que cada professor, individualmente, usa seu método e conduz suas aulas da maneira que acredita ser melhor: "Acho que cada professor faz sua parte sozinho." (Entrevistada B).

Deste modo, considerou-se extremamente importante a colocação da professora acima, que aponta para o esforço individual de cada professor para lidar com as questões da convivência, tendo em vista que a preocupação com estas questões deveria ser da escola de modo integral, não de uns poucos interessados. As professoras que fazem algo para discutir e melhorar a convivência tomam por ações individuais algo que deveria ser coletivo e isso pode gerar, inclusive, um desgaste, um sentimento de desistência ou uma considerável de falta de motivação na classe de professores.

Compreendendo a convivência democrática como tarefa difícil, porém essencial para o funcionamento cooperativo da sala de aula, a falta de apoio dada aos professores e a grande quantidade de tempo e esforço que são necessárias, acabam sendo grandes motivo para a desistência. Além disso, o desinteresse dos colegas e dos alunos acaba, muitas vezes, prejudicando a motivação desses educadores que tentam melhorar o ambiente e a aprendizagem.

Além disso, é importante destacar que em nenhum outro momento da história os educadores tiveram um desafio perto do atual: aprender e ensinar a viver num mundo cada vez 
mais saturado de informações. Preparar os alunos para entrarem nessa realidade quase caótica é uma tarefa árdua, mas fazê-los prestar atenção na sala de aula, enquanto sabem que nas redes há inúmeras novidades a cada instante, é mais trabalhoso ainda (BAUMAN, 2011). Por isso, compreende-se que muitos professores acabem recorrendo àquelas antigas formas de ensinar baseadas nos excessos de disciplina e de autoritarismo.

Quando isso ocorre, mas o aluno não segue seu papel definido de escutar, obedecer, não questionar e submeter-se, o professor acaba agindo conforme o seu de saber, ordenando, decidindo e, se necessário, punindo (BOCK, 2008). Por ser um sistema hierarquizado, funcionando com uma rede de relações de alto a baixo, que perpassa efeitos de poder que se apoiam uns sobre os outros (FOUCAULT, 1987), quando o controle escapa de suas mãos e a convivência torna-se difícil, os professores acabam recorrendo ao auxílio da coordenação ou da direção, ou seja, os níveis mais altos nessa pirâmide escolar:

"É uma coisa que puxa a outra, a gente tá sempre né, ou então às vezes quando a gente não consegue em sala de aula, entra a direção pra tentar resolver aqueles problemas... aqueles pontuais, mas a gente tá sempre tentando né, nesse sentido." (Entrevistada A).

Considera-se importante a colocação acima, pois traz a diversidade de questões com as quais a coordenação e a direção escolar acabam se envolvendo na escola em questão. Estas têm funções relacionadas à gestão em si, mas acabam envolvidas na resolução desses problemas "pontuais" de dificuldades de convivência, de desordem ou indisciplina dentro das salas de aula. Pontua-se aqui a necessidade de que pudessem ser discutidas as questões de convivência na escola não de maneira pontual, como acaba sendo feito, mas de modo amplo, instigando os estudantes a participarem das discussões e das decisões na escola e na sala de aula. Entende-se que, deste modo, possa-se capacitar os estudantes a atuarem ativamente na sociedade de maneia respeitosa e democrática.

Conclui-se que, apesar de tentativas por parte de certos professores, a hierarquia presente na atual organização escolar parece exigir o exercício do autoritarismo e da disciplina estéril, que educam para a passividade e a obediência (ARANHA, 2006), o que acaba tornando mais frágil a participação ativa e a convivência democrática nos espaços escolares.

\section{Considerações Finais}

O presente trabalho buscou discorrer sobre a importância conferida pelas professoras às questões relacionadas à convivência democrática no espaço escolar. Como resultados, pode-se 
dizer que, embora algumas professoras entrevistadas tenham apontado que a disciplina ainda seja um meio de funcionamento ainda presente na educação atual, entendeu-se que encarar e discutir sobre a questão da convivência escolar é algo extremamente necessário na atualidade. Percebeu-se a escola como um dos espaços mais importantes para essa discussão, um lugar privilegiado para promover, desde cedo, uma convivência respeitosa e democrática.

Todas as entrevistadas possuem a convivência como questão em suas salas de aula, porém devido a grande individualização existente, enquanto algumas sobrecarregam-se tentando lidar com esse problema da melhor maneira possível, trabalhando, ensinando; outras repassam a responsabilidade para as outras esferas, tanto para a coordenação, quanto para as famílias. Aponta-se para a necessidade de que as questões da convivência na escola pudessem ser trabalhadas e discutidas de modo coletivo, para não sobrecarregar as professoras, e também, principalmente, porque considera-se que a própria discussão em grupo consolida uma troca de ideias e experiências importante para fortalecimento do convívio democrático.

Como já mostrado em trabalho anterior, há ainda uma fragilidade nas definições, por parte do corpo docente, do conceito de educação e sua relação com as questões de convivência e, especialmente, uma fragilidade nas reflexões sobre seu próprio fazer cotidiano (ZUCOLOTTO; LIMACHI; NASS, 2019a). Assim, a educação para a convivência democrática é uma questão muito complexa e não deve ser função exclusiva da escola, nem da família. Ambas instituições devem trabalhar em parceria para obter êxito.

Deste modo, conclui-se, com Bauman e Mazzeo (2013, p. 20) que "embora os poderes do atual sistema educacional pareçam limitados, e ele próprio seja cada vez mais submetido ao jogo consumista, ainda tem poderes e transformação suficientes para ser considerado um dos fatores promissores para essa revolução". Reitera-se a importância basilar da escola como instituição capaz de contribuir significativamente para construção de uma sociedade mais respeitosa e democrática.

\section{Referências}

ARANHA, M. L. A. Filosofia da educação. 3. ed. São Paulo: Moderna, 2006.

BARDIN, L. Análise de Conteúdo. Lisboa: Edições 70, 2010.

BAUMAN, Z. 44 cartas do mundo líquido moderno. Rio de Janeiro: Jorge Zahar Editor, 2011.

BAUMAN, Z.; MAZZEO, R. Sobre educação e juventude: conversas com Riccardo Mazzeo. Rio de Janeiro: Jorge Zahar Editor, 2013. 
BRASIL. Ministério da Saúde. Conselho Nacional de Saúde. Resolução no 510, de 7 de abril de 2016. Diário Oficial da República Federativa do Brasil, Brasília, DF.

BOCK, A. M. B. A Escola. In: BOCK, A. M. B. Psicologias: uma introdução ao estudo de psicologia. 14a. ed. São Paulo: Saraiva, 2008.

CANDAU, V. (Org.). Somos tod@s iguais? Escola, discriminação e educação em direitos humanos. Rio de Janeiro: DP\&A, 2003.

FOUCAULT, M. Vigiar e punir: o nascimento da prisão. 22a ed. Petrópolis: Vozes, 1987.

MOSÉ, V. A escola e os desafios contemporâneos. Rio de Janeiro: Civilização Brasileira, 2013.

SILVA, R. M. D.; BUSNEllo, C. P.; PEZENATTO, F. Política, cidadania e educação integral: a convivência democrática como princípio pedagógico. Rev. Bras. de Política e Administração da Educação. v. 30, n. 2, pp. 397-416, 2015.

STAKE, R. E. Pesquisa qualitativa: estudando como as coisas funcionam. Porto Alegre: Penso, 2011.

ZUCOLOTTO, M. P. R.; LIMACHI, E. K. U.; NASS, I. R. Conceituando educação: o que pensam professores do ensino fundamental. In: Anais do Seminário Internacional de Ensino de Humanidades e Linguagens, Santa Maria: Universidade Franciscana, v. 2, 2019a.

ZUCOLOTTO, M. P. R.; LIMACHI, E. K. U.; NASS, I. R. Conviver na escola: o princípio de uma sociedade democrática. In: Anais do Simpósio de Ensino, Pesquisa e Extensão - SEPE, Santa Maria: Universidade Franciscana, v. 11, n. 23, 2019 b.

ZUCOLOTTO, M. P. R.; LIMACHI, E. K. U.; NASS, I. R. Produção de subjetividades e convivência escolar. Research, Society and Development, v. 8, n. 6, pp. 1-17, 2019c.

Artigo recebido em: 11/07/2020. Artigo aceito em: 27/07/2020. 